\title{
As vozes insurgentes são feministas
}

\author{
Insurgent Voices are Feminists \\ Leonardo Ferreira Peixoto' (id) 0000-0002-4817-1701 \\ Larissa Pelúcio 2 (iD) 0000-0001-6212-3629 \\ 'Universidade do Estado do Amazonas, Tabatinga, AM, Brasil. \\ 69640-000-reitor@uea.edu.br \\ 2Universidade Estadual Paulista "Júlio de Mesquita Filho", Bauru, SP, Brasil. \\ 17033-360-diretor@faac.unesp.br
}

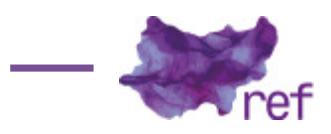

"Se cuida, se cuida, se cuida, seu machista, a América Latina vai ser toda feminista", o grito ecoou pelas ruas de Porto Alegre que fervilhavam no calor de 40 graus. Era o ano de 2003, a Marcha Mundial das Mulheres (MMM) acontecia no contexto do Terceiro Fórum Social Mundial. Embalada pela Batucada Feminista, que fazia sua estreia naquele ano, jovens feministas se somaram ao movimento de mulheres lésbicas, travestis e homens gays na Marcha da Diversidade contra a Guerra e Pela Paz, compondo mais uma frente à MMM.

\begin{abstract}
O bloco da Marcha Mundial das Mulheres, incansável à frente da passeata, foi um daqueles momentos especiais em que a ação coletiva vale por dez oficinas de formação, especialmente para as jovens. Quantas delas, nesses tempos de tanta miséria e de tanto remédio para emagrecer, têm a oportunidade de sair na rua em bloco, batendo tambor e gritando gostosamente "SOMOS MULHERES E NÃO MERCADORIA!"? [...] Todas - as militantes da Marcha, as habitantes do Acampamento [da Juventude], as que chegaram desavisadas - saíram daquela marcha um pouco mais feministas do que entraram (Júlia Ruiz DI GIOVANNI, 2003, p. 655-656, destaque nosso).
\end{abstract}

Sete anos depois, pesquisa realizada pela Fundação Perseu Abramo mostraria que Júlia Ruiz Di Giovanni, autora do texto do qual extraímos o fragmento acima, estava certa. Entre 2001 a 2010 o contingente de brasileiras que se considera feministas aumentou de $21 \%$ para $31 \%$. As adolescentes foram as que mais se reconheceram como tal (40\% entre 15 e 17 anos), "seguidas das jovens de 25 a 34 anos, com 37\% de identificação" (Carla GOMES; Bila SORJ, 2014, p. 434). Isto é, mulheres que tinham entre 08 e 27 anos quando aquelas palavras de ordem foram sincopadas pelo ritmo do Batuque Feminista, naquele dia quente de 2003. Os ecos dos debates feministas mostravam seus efeitos.

Nas últimas duas décadas, assistíamos a uma maior capilarização do feminismo na sociedade brasileira impulsionada pela chegada ao poder de um partido cujas bases estiveram historicamente sustentadas em movimentos sociais.

A partir do Executivo, com destaque para a atuação da Secretaria de Políticas para Mulheres e para as estratégias de ação traçadas nas Conferências de Políticas para as Mulheres (2004; 2007; 2011; 2016), mas também a partir de decisões conquistadas no âmbito do Judiciário e de alianças pontuais no Legislativo, os movimentos feministas produziram avanços importantes, entre os quais cito, a título de exemplo, a Lei Maria da Penha (Lei $n^{\circ} 11.340 / 2006$ ), sancionada em 2006, que permitiu institucionalizar e ampliar o combate à violência doméstica numa perspectiva de gênero; as Normas Técnicas do Ministério da Saúde para garantia do acesso das mulheres ao aborto nos casos previstos por lei; a Proposta de Emenda Constitucional (PEC) $72 / 2013$, conhecida como PEC das Domésticas, regulamentada em junho de 2015, que equaliza os direitos das trabalhadoras domésticas aos de outros trabalhadores, lembrando que, no Brasil, 
$98 \%$ das pessoas que exercem trabalho doméstico remunerado são mulheres; a Lei do Feminicídio (Lei n 13.104/2015), sancionada em março de 2015 (Flávia BIROLI, 2018, p. 77).

Esses elencos de avanços interseccionam gênero a classe social, raça e sexualidade, marcadores encarnados no corpo e na luta de Marielle Franco, a quinta vereadora mais votada para a Câmara Municipal do Rio de Janeiro em 2016, mesmo ano em que Dilma Rousseff seria deposta, sem provas, da presidência da República, seria assassinada dois anos depois. Os tiros que mataram Marielle deram a largada para um tempo de retrocessos.

A perspectiva intersecional apareceu também no último pronunciamento de Rousseff. Antes de deixar o poder em definitivo, a única mulher presidenta do Brasil, em 122 anos de República, denunciava: "o golpe é contra o povo e contra a Nação. O golpe é misógino. O golpe é homofóbico. O golpe é racista. É a imposição da cultura da intolerância, do preconceito, da violência" (Dilma ROUSSEFF apud Clério JÚNIOR, 2016, p. 200).

Gênero como categoria política tornou-se decisivo nas disputas eleitorais desde 2010 e mostrou sua potência durante o período que antecedeu o golpe parlamentar de 2016. Rousseff foi deposta também por ser mulher. Em Mídia, Misoginia e Golpe (2016), Elen Cristina Geraldes, Tânia Regina Oliveira Ramos, Juliano Domingues da Silva, Liliane Maria Macedo Machado e Vanessa Negrini reuniram 53 entrevistas com diferentes "personalidades acadêmicas e políticas com importantes contribuições neste debate, seja na mídia ou em outros palanques" (Elen Cristina GERALDES et al., 2016) que, entre outras questões, foram convidadas a responder se a misoginia colaborou para o desfecho de Rousseff. A maioria respondeu que "questões de gênero, a misoginia, o sexismo, a herança de uma cultura que se forjou no patriarcado, foram ingredientes [...] de grande relevância para influenciar a opinião pública durante a cobertura do processo de impeachment" (Idem).

Parece que, em 2016, vivíamos a ressaca de 2015, ano nomeado pela grande imprensa e por movimentos sociais de mulheres como a "Primavera Feminista" (Alcileide NASCIMENTO, 2018; Milena BRITO, 2017; Rose Marie SANTINI, Camyla TERRA, Alda Rosa ALMEIDA, 2016; Bárbara OLIVEIRA, Franciele SILVA, 2016). A Primavera conectou pautas históricas do movimento de mulheres e feministas como a discriminação do aborto, às mais recentes, como aquelas ensaiadas já em 2003, que associavam os feminismos a outros movimentos que se batiam pelos direitos de grupos sociais historicamente subalternizados.

Munidas de hashtags e com seus corpos pintados, milhares de mulheres de todo país se organizaram contra o assédio sexual e a "cultura do estupro", sinalizando que certos comportamentos masculinos dirigidos às meninas e às mulheres seriam, doravante, denunciados e combatidos. De forma que

[v]árias irrupções perturbaram esse sentimento de caminhar em território conhecido, em especial para o homem branco e heterossexual. As mulheres disseram a eles com uma ênfase inédita que não seria mais possível fazer gracinhas nas ruas nem assediá-las no trabalho ou em qualquer lugar. A violência sexual foi exposta e reprimida. A violência doméstica, quase tão comum quanto o feijão com arroz ("um tapinha não dói") foi confrontada pela Lei Maria da Penha. Afirmar que uma "mulher era mal comida" se tornou comentário inaceitável de um neandertal (Eliane BRUM, 2019).

O "homem mediano", adjetivação dada por Eliane Brum (2019) a Jair Bolsonaro, chegou ao poder pelo voto popular, instalando a tirania do óbvio (Keila DESLANDES, 2019), operando com afirmações lineares de crenças e opiniões dominantes, desqualificando elaborações teóricas que demandem reflexão e crítica. Daí o anti-intelectualíssimo flagrante do bolsonarismo, avesso também às políticas inclusivas, igualitárias e de alargamento das margens contritas de nossa débil democracia. Na resistência, estiveram as mulheres, gritando \#elenão!

Grito que ecoa nas páginas deste dossiê, no qual acadêmicas e ativista se encontram em reflexões ensaísticas e em textos derivados de pesquisas científicas. Em todo o material aqui reunido encontramos a influência dos estudos feministas. Gênero e sexualidade são chaves analíticas para compreender e problematizar o contexto brasileiro contemporâneo, mostrando sua espessura política.

Nas discussões feitas pelas autoras que compõem este dossiê, se evidencia não só a resistência feminista contra o conservadorismo político que, nos últimos dois anos, engolfou tantos países no mundo, como também mostram que esta onda é claramente antifeminista. Suas vozes e escrituras são corais vivos que buscam conter essa maré anti-igualitária e avessa aos direitos humanos.

A linha do tempo traçada pelos textos deste dossiê começa nas primeiras edições nacionais das Marchas das Vadias e se estende até o movimento \#elenão, passando pelo impeachment de Dilma Rousseff e pelo assassinato de Marielle Franco. Tece-se, assim, um cenário tão potente quanto desestabilizador, para o qual a resposta foi violentamente misógina: golpe, assassinato, feminicídios e uma ministra que assume o Ministério da Mulher, da Família e dos Direitos Humanos, opondo-se às pautas históricas das lutas feministas. 
A coletânea de artigos, ensaio e entrevista reunidas neste dossiê começou a ser gestada logo após o resultado das eleições presidenciais de 2018, publicada dois anos depois, ainda guarda o calor da hora, de forma que muito do que apresentamos aqui é também um retrato de um momento de profundas disputas e tensões.

Abrimos este dossiê com o ensaio Manifestações textuais (insubmissas) travesti. As autoras Sara Wagner Pimenta Gonçalves Júnior, Bruna Benevides e Megg Rayara Gomes de Oliveira apresentam-no, a partir de o "pensamento travesti" como proposta de reflexões políticoepistemológicas. O transfeminismo e transativismo aparecem como marcos de luta para um futuro travesti, no qual a resistência encontra com afeto e com práticas transformadoras que possam reverberar em todas as esferas da vida. Provocativamente, o pensamento travesti denuncia a violência perpetrada sobre vidas trans ao mesmo tempo em que celebra os corpos (e mentes) insubmissos.

Flávia Melo, em Não é fumaça, é fogol Cruzada antigênero e resistências feministas no Brasil, mostra como a politização de temas associados à democracia sexual e à igualdade de gênero foram capturados por setores conservadores. Melo remonta à construção da agenda moral, que ganhou a cena em 2014, com a cruzada antigênero nos Planos Municipais, Estaduais e Nacional de Educação e alcançou sua mais expressiva vitória no impeachment de Dilma Roussef. A marcha conservadora encontra resistência, mas também se alimenta dos movimentos de mulheres e feministas que tomam as ruas em 2015, "a primavera feminista". No ápice destas tensões em torno das questões de gênero, a autora identifica o movimento \#elenão. A rede encontra-se com a rua. Ao mapear os movimentos das hashtags feministas ao grito de rechaço a Jair Bolsonaro, Melo procura desmontar o que chama de falsa dicotomia entre pautas identitárias versus economia.

Maria Luiza Süssekind, Stephanie Nascimento e Lorena Azevedo, no artigo intitulado 'Alfinetar': currículos, ódios e gêneros, apresentam a Prova Platô como uma estratégia reflexiva da disciplina Currículo, um dos componentes curriculares dos cursos de pedagogia e licenciaturas da Universidade Federal do Estado do Rio de Janeiro/UNIRIO. Naquele espaço anônimo de expressão e reflexão, estudantes são convidadas e convidados a avaliar sua formação, as disciplinas e os currículos, mas vão além. Falam se si, das suas dores, incômodos e recusas. Aparecem, então, os discursos que "alfinetam" as autoras. Manifestações racista, misóginas, homofóbicas, classistas apareceram na Prova Platô, numa colagem de ideias que vai ser remontada num minucioso quebra-cabeças crítico-questionador por Süssekind e Azevedo.

\#Paslui: feminismo brasileiro no hexágono europeu fecha a seção de artigos. Escrito por Larissa Pelúcio e Diego Paz, o texto faz uma fotografia do movimento \#elenão em suas reverberações em contexto francês, tomando o conceito butleriano de political agency para pensar na luta durante o processo eleitoral e no luto após a vitória da extrema-direita no Brasil. $O$ texto parte de imersões etnográficas da autora e autor nas manifestações que aconteceram na cidade de Paris, na França, no período das eleições de 2018 no Brasil, mas também de entrevistas com as organizadoras locais dos eventos. As autoras argumentam que este movimento, iniciado pelas mulheres, foi um elemento unificador de outras minorias políticas, como negras e negros e LGBT+, contra o avanço do "populismo de direita" e retrocessos no campo dos direitos humanos.

Encerramos este dossiê com a emoção do diálogo organizado em forma de entrevista entre Leonardo Peixoto, um dos organizadores desta Seção, com a única filha de Marielle Franco, Luyara Franco. "Quem mandou matar Marielle?" - uma conversa com Luyara Franco é um testemunho narrado 550 dias após o assassinato de Marielle, ocorrido em 14 de março de 2018. O texto apresenta uma conversa afetuosa e carinhosa entre duas pessoas que compartilham a dor da morte da parlamentar, de um lado um companheiro de militância e do outro a filha de Marielle. As narrativas são marcadas pela dor da perda, por dúvidas e incertezas quanto à ausência de respostas na investigação, sobre a importante influência que mãe e filha tinham uma na vida da outra e sobre as sementes, ações encampadas por familiares, sociedade civil e parlamentares após a execução de Marielle Franco.

Os textos que compõem esta Seção Temática ampliam e aprofundam reflexões com a politização de pautas históricas dos movimentos de mulheres e feministas, bem como daqueles que vêm lutando por direitos sexuais e civis de pessoas que desafiam com seus corpos os limites das epistêmes e culturas hegemônicas. Esperamos que as leitoras e leitores se permitam questionálas, problematizá-las e enriquecê-las com suas leituras.

\section{Referências}

BIROLI, Flávia. "Uma mulher foi deposta: sexismo, misoginia e violência política". In: RUBIM, Linda; ARGOLO, Fernanda (Orgs.). O golpe na perspectiva de gênero. v. 1, 1. ed. Salvador: EDUFBA, 2018. p. 75-84.

BRITO, Milena. "Primavera Feminista: A Internet e as Manifestações de Mulheres em 2015 no Rio de Janeiro". SEMINÁRIO INTERNACIONAL FAZENDO GÊNERO 11 \& 13TH WOMEN'S WORLDS CONGRESS, 2017, Florianópolis, UFSC, Anais... Florianópolis: UFSC/Instituto de Estudos de Gênero, 2017. p. 1-11. 
BRUM, Eliane. "O homem mediano assume o poder. O que significa transformar o ordinário em 'mito' e dar a ele o Governo do país?". El País, 2019. Disponível em https://brasil.elpais.com/brasil/2019/ 01/02/opinion/1546450311_448043.html. Acesso em 26/04/2020.

DESLANDES, Keila. "Sobre disputas anti-igualitárias e políticas públicas: mais argumentos para o debate". Interface, Botucatu, v. 23, Epub June 13, 2019. Disponível em: http://www.scielo.br/ scielo.php?pid=S1414-32832019000100402\&script=sci_arttext. Acesso em 20/04/2020.

DI GIOVANNI, Julia Ruiz. "Jovens, feministas, em movimento: a Marcha Mundial das Mulheres no III Acampamento Intercontinental da Juventude". Revista Estudos Feministas, Florianópolis, v. 11 , n. 2, p. 655-660, dez. 2003. Disponível em http://www.scielo.br/scielo.php?script=sci_arttext\&pid=S0104026X2003000200024\&lng=en\&nrm=iso. Acesso em 27/04/2020.

GERALDES, Elen Cristina et al. (Orgs.). Mídia, misoginia e golpe. Brasília, DF: FACUnB, 2016.

GOMES, Carla; SORJ, Bila. “Corpo, geração e identidade: a Marcha das vadias no Brasil”. Sociedade e Estado, Brasília, v. 29, n. 2, p. 433-447, ago. 2014. Disponível em http://www.scielo.br/scielo.php? script $=$ sci_arttext\&pid=S0102-69922014000200007\&lng=en\&nrm=isso. Acesso em 20/03/2020.

JÚNIOR, Clério O. S. O Dia Do Golpe: A Farsa Propagada Pela Mídia Brasileira. Create Space/ Kindle, 2016.

NASCIMENTO, Alcileide Cabral do. "A primavera feminista. Vozes de luta da emancipação feminina no Brasil e Uruguai". Revista Estudos Feministas, Florianópolis, v. 26, n. 2, e57191, 2018. Disponível em https://www.scielo.br/scielo.php?script=sci_arttext\&pid=S0104-026X2018000200601. Acesso em 28/07/2020.

OLIVEIRA, Bárbara N.; SILVA, Franciele J. G. "Feminismo nas Mídias Sociais: Atualidades e Potencialidades". SEMINÁRIO NACIONAL DE SOCIOLOGIA DA UFS, 1, 2016, São Cristóvão, UFS. Anais... São Cristóvão: EdUFS/PPGS, 2016. p. 796-809.

SANTINI, Rose Marie; TERRA, Camyla T.; ALMEIDA, Alda Rosa. "Feminismo 2.0: A Mobilização das Mulheres no Brasil Contra o Assédio Sexual Através das Mídias Sociais (\#Primeiroassedio)". P2P Inovação, v. 3, p. 148-164, 2016. Disponível em http://revista.ibict.br/p2p/article/view/2341/2390. Acesso em 28/07/2020.

Leonardo Ferreira Peixoto (leopeixoto.uea@gmail.com) é doutor em Educação pela Universidade do Estado do Rio de Janeiro, Professor da Universidade do Estado do Amazonas, coordenador do Grupo de Pesquisa Redes Indígenas: povos indígenas e redes educativas. Membro da Associação Brasileira de Currículo e do GT de Currículo da Associação Nacional de PósGraduação e Pesquisa em Educação-ANPEd.

Larissa Pelúcio (larissa.pelucio@unesp.br) é Livre-Docente em Estudos de Gênero, Sexualidade e Teorias Feministas. Atua como Professora de Antropologia na Universidade Estadual Paulista Júlio de Mesquita Filho. Doutora em Ciências Sociais pela Universidade Federal de São Carlos (UFSCar), realizou Pós-doutorado na Université Paris 8 - Vincennes - Saint Denis. Suas pesquisas abordam temas como gênero, sexualidade, saúde, mídias digitais a partir de diálogos com a teoria queer, as epistemologias feministas e os Saberes subalternos. 
COMO CITAR ESSE ARTIGO DE ACORDO COM AS NORMAS DA REVISTA

PEIXOTO, Leonardo Ferreira; PELÚCIO, Larissa. "As vozes insurgentes são feministas". Revista Estudos Feministas, Florianópolis, v. 28, n. 3, e72260, 2020.

\section{CONTRIBUIÇÃO DE AUTORIA}

Autor e autora contribuíram igualmente.

\section{FINANCIAMENTO}

Não se aplica.

\section{CONSENTIMENTO DE USO DE IMAGEM}

Não se aplica.

APROVAÇÃO DE COMITÊ DE ÉTICA EM PESQUISA

Não se aplica.

\section{CONFLITO DE INTERESSES}

Não se aplica.

\section{LICENÇA DE USO}

Este artigo está licenciado sob a Licença Creative Commons CC-BY Internacional. Com essa licença você pode compartilhar, adaptar, criar para qualquer fim, desde que atribua a autoria da obra.

\section{HISTÓRICO}

Recebido em 19/03/2020

Aprovado em 17/08/2020 